\title{
Time-Resolved Spectroscopy Diagnostic of Laser-Induced Optical Breakdown
}

\author{
Christian G. Parigger, ${ }^{1}$ James O. Hornkohl, ${ }^{1}$ and László Nemes ${ }^{2}$ \\ ${ }^{1}$ Center for Laser Applications, The University of Tennessee Space Institute, 411 B.H. Goethert Parkway, Tullahoma, TN 37388, USA \\ ${ }^{2}$ Chemical Research Center of the Hungarian Academy of Sciences, Pusztaszeri ut 59-67, 1025 Budapest, Hungary
}

Correspondence should be addressed to Christian G. Parigger, cparigge@tennessee.edu

Received 7 April 2009; Accepted 24 July 2009

Academic Editor: Roland Stamm

Copyright (C) 2010 Christian G. Parigger et al. This is an open access article distributed under the Creative Commons Attribution License, which permits unrestricted use, distribution, and reproduction in any medium, provided the original work is properly cited.

\begin{abstract}
Transient laser plasma is generated in laser-induced optical breakdown (LIOB). Here we report experiments conducted with 10.6micron $\mathrm{CO}_{2}$ laser radiation, and with 1.064-micron fundamental, 0.532-micron frequency-doubled, 0.355-micron frequencytripled Nd:YAG laser radiation. Characterization of laser induced plasma utilizes laser-induced breakdown spectroscopy (LIBS) techniques. Atomic hydrogen Balmer series emissions show electron number density of $10^{17} \mathrm{~cm}^{-3}$ measured approximately $10 \mu \mathrm{s}$ and $1 \mu \mathrm{s}$ after optical breakdown for $\mathrm{CO}_{2}$ and $\mathrm{Nd}$ :YAG laser radiation, respectively. Recorded molecular recombination emission spectra of $\mathrm{CN}$ and $\mathrm{C}_{2}$ Swan bands indicate an equilibrium temperature in excess of 7000 Kelvin, inferred for these diatomic molecules. Reported are also graphite ablation experiments where we use unfocused laser radiation that is favorable for observation of neutral $\mathrm{C}_{3}$ emission due to reduced $\mathrm{C}_{3}$ cation formation. Our analysis is based on computation of diatomic molecular spectra that includes accurate determination of rotational line strengths, or Hönl-London factors.
\end{abstract}

\section{Introduction}

Laser-induced breakdown spectroscopy (LIBS) is a valuable technique for determining elemental composition with the ability to analyze solids, liquids, and gases with little or no sample preparation suitable for onsite analyses [1]. The success of LIBS is in part due to the ease of availability of nominal 10-nanosecond Nd:YAG laser radiation from compact devices. Several other laser sources however have been historically applied for generation of microplasma with subsequent measurement methods based on use of atomic emission spectroscopy [2]. Recent interest includes applying dual- and multipulse excitation for the purpose of increasing sensitivity of LIBS. Examples of advantages of multipulse excitation include an increase of the plasma volume or plasma reheating by the second pulse, in turn, enhancement of detection limits for LIBS 10- to 100-fold and/or a decrease in relative standard deviation when comparing single- with double- pulse bursts [3]. Following short-pulse UV-excitation a $\mathrm{CO}_{2}$ laser may be used to enhance detection from a distance of atomic and molecular species [4-6]. Some applications are also designed with eye-safety in mind, required for remote and/or field-safe LIBS systems $[7,8]$. Applications of $\mathrm{CO}_{2}$ lasers also include aerosol measurements $[9,10]$.

In this work, we utilize a $\mathrm{CO}_{2}$ transversely excited atmospheric-pressure (TEA) laser at the 10.6-micron wavelength to generate the LIBS plasma. The $\mathrm{CO}_{2}$ laser-induced plasma is expected to show a larger homogenous core than the Nd:YAG plasma. This is primarily due to prolonged, intensive, and spatially extended excitation that masks the temporal and spatial variation of the $\mathrm{CO}_{2}$ laser beam from pulse to pulse. Recorded atomic and molecular emission spectra are evaluated and compared with diagnostics that we applied previously for characterization of Nd:YAG laserinduced microplasma [11].

For laser ablation studies, we use the Nd:YAG laser operated in the second and third harmonic radiation modes. Graphite laser-ablation is one possible process that can lead to carbon nanoparticle formation $[12,13]$. The laser-plasma 
conditions during the nominal nanosecond laser exposure during ablation can be measured by recording temporally and spatially averaged spectra. In this work, time-resolved methods are applied to investigate the evolution of $\mathrm{C}_{2}$ and $\mathrm{C}_{3}$ formation. In addition, the carbon layer is studied which is deposited at the walls of our Laser-Induced Breakdown Spectroscopy (LIBS) cell. The application of visible absorption spectroscopy and transmission electron microcopy allows us to reach conclusions about the graphite ablation product.

\section{Experimental Details}

The experimental arrangement is identical to a standard LIBS setup, that is, laser, spectrometer, detector-system, and a sample. The $\mathrm{CO}_{2}$ laser experiment details are as follows: the $\mathrm{CO}_{2}$ laser is the model TEA-820 Lumonics, the spectrometer is the $1 / 2$ meter model 500 SpectraPro Acton Research Corporation, and the detector is the intensified model 1460 EG\&G Princeton Applied Research detector/controller Optical Multichannel Analyzer (OMA). The laser plasma is first generated for alignment purposes and initial diagnostic studies in laboratory air using $f / 4$ focusing. The plasma is then generated in $\mathrm{CO}_{2}$ gas expanding into the focal volume at a rate of $10 \mathrm{~L} / \mathrm{m}$ into the laboratory. Survey spectra from laser-induced optical breakdown (LIOB) in CO gas are reported here.

Typical operating parameters of our $\mathrm{CO}_{2}$ TEA laser are (i) pulse width of 70-100 ns full-width at half-maximum, or 10x longer than Nd:YAG pulses, (ii) pulse energy of 2000-3000 mJoule, or typically 10-100x larger than nominal $\mathrm{Nd}$ :YAG laser devices, and (iii) wavelength of $10.6 \mu \mathrm{m}$, or 10x longer than the $1.064 \mu \mathrm{m}$ of the fundamental Nd:YAG laser radiation.

The Nd:YAG laser experiment details are as follows: the Nd:YAG laser is the model $10 \mathrm{~Hz}$ Quantel Brilliant operated in the second and third harmonic modes at 532 and $355 \mathrm{~nm}$, respectively. The laser-induced plasma was created using unfocussed radiation impinging upon a $10 \mathrm{~mm}$ diameter spectrally pure graphite pellet that was cut from a graphite rod. The target was shifted from measurement set to measurement set, but was kept stationary during individual experiments.

The laser pulse energy and pulse-width of the fundamental mode $(1064 \mathrm{~nm})$ was adjusted electronically by changing the delay between the flash-lamp and the Qswitch trigger. At an optimum delay $(190 \mu \mathrm{s})$, the laser pulse energy amounted to $120 \mathrm{~mJ}$ at $532 \mathrm{~nm}$, and $60 \mathrm{~mJ}$ at $355 \mathrm{~nm}$. Electronic adjustments of the Q-switch trigger allowed us to reduce the energy per pulse by a factor of 3 . An argon background gas was used at various pressures between 10 and 200 Torr.

Time-resolved emission spectra were taken using the model Andor Technology IStar ICCD and the associated Andor Shamrock spectrograph. The detection system shows a temporal resolution of $\sim 10 \mathrm{~ns}$. The overall spectral resolution amounted to $8 \mathrm{~nm}$ and $1 \mathrm{~nm}$ for the 150 grooves $/ \mathrm{mm}$ and $1200 \mathrm{~g} / \mathrm{mm}$ grating, respectively. No entrance slit was

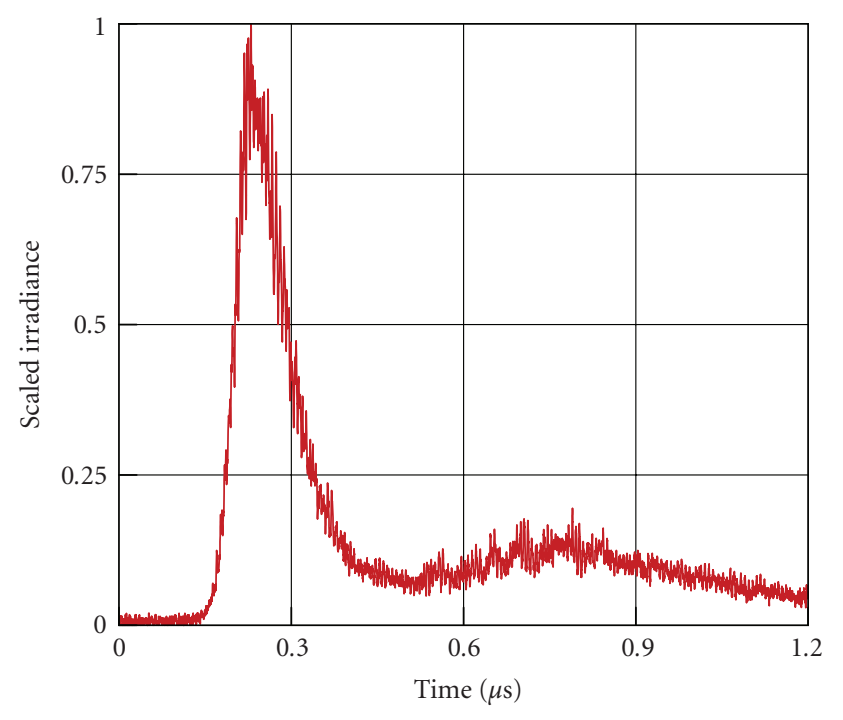

FIGURE 1: Measured pulse width of $0.1 \mu \mathrm{s}$ FWHM for $\mathrm{CO}_{2}$ laser radiation, with a $1 \mu$ s tail at $10 \%$ of maximum, scaled irradiance.

used for the spectrometer, instead we employed a 50-micron optical fiber.

\section{Experimental Results}

Temporal characteristics of $\mathrm{CO}_{2}$ TEA laser radiation include a reasonably steep rise-time followed by an extended tail. Figure 1 shows a recorded pulse profile.

The emissions from the plasma are strong enough to allow us to monitor spectra from single breakdown events; however, we elected to average over 50 individual laser-plasma events. Typical recorded atomic and molecular spectra are illustrated in what follows.

Figure 2 shows the recorded and fitted spectrum of the $\mathrm{CN} \Delta \nu=0$ sequence of the $\mathrm{CN} \mathrm{B}^{2} \Sigma^{+} \rightarrow \mathrm{X}^{2} \Sigma^{+}$Violet System. The spectral resolution amounted to $0.12 \mathrm{~nm}$ when using the 2400 grooves/mm grating. Particularly strong CN emissions occur and dominate the molecular emissions in the visible region when using $\mathrm{CO}_{2}$ flow expanding into laboratory air. We used a gate width of $20 \mu$ s and a time delay of $20 \mu$ s. The inferred temperature amounts to $\mathrm{T}=7220 \mathrm{~K}$, using our fitting routines for diatomic spectra [14-16]. Figure 2 also shows an insert near the wavelength region of 4-4 band of $\mathrm{CN}$ that we excluded in the fitting routine. The additional spectroscopic feature indicates presence of the $\mathrm{C}_{2}$ Deslandres D'Azambuja system [17].

Figure 3 shows the recorded spectrum of the $\mathrm{C}_{2} \Delta \nu=0$ sequence of the $d^{3} \Pi_{g} \rightarrow a^{3} \Pi_{u}$ Swan bands. The spectral resolution amounts to $0.4 \mathrm{~nm}$ for the $1200 \mathrm{~g} / \mathrm{mm}$ grating. Also indicated are atomic carbon lines [18], recorded for a delay time of $10 \mu \mathrm{s}$ after optical breakdown, using an intensifier gate width of $100 \mu \mathrm{s}$. After subtraction of the atomic signatures and/or exclusion of regions with atomic lines, fitting of the molecular spectra may be accomplished using our standard fitting procedures [19, 20]. Results of $\mathrm{C}_{2}$ Swan bands fitting (not illustrated here) for $20 \mu \mathrm{s}$ time 


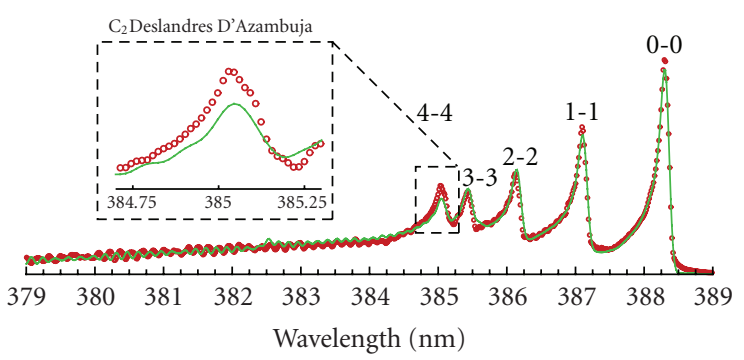

Figure 2: Measured (circles) and fitted (solid line) spectrum of the $\mathrm{CN} \Delta \nu=0$ sequence of the $\mathrm{CN} \mathrm{B}^{2} \Sigma^{+} \rightarrow \mathrm{X}^{2} \Sigma^{+}$Violet System. The insert indicates emission from the $\mathrm{C}_{2}$ Deslandres D'Azambuja system.

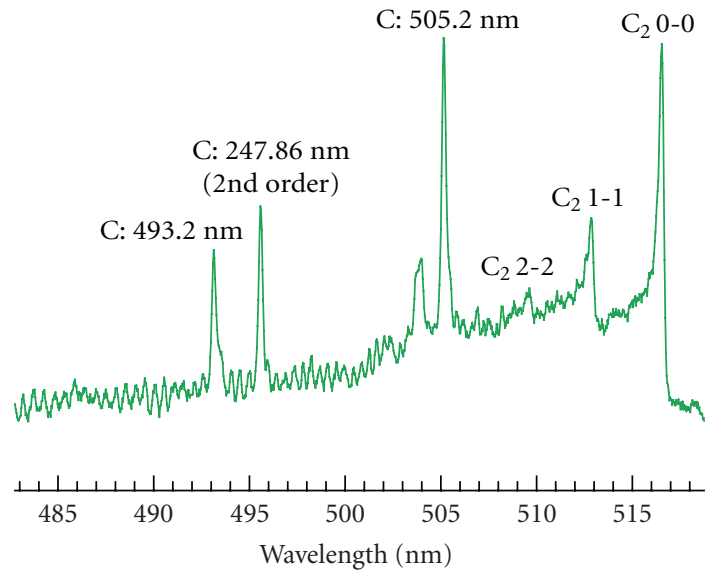

Figure 3: Recorded $\mathrm{C}_{2}$ Swan bands and atomic carbon lines with $\mathrm{CO}_{2}$ flow.

delay and $20 \mu$ s gate-width (compare Figure 2) indicate a temperature of $\mathrm{T}=7230 \mathrm{~K}$.

In our fitting procedures of diatomic molecular spectra [16], we usually employ local thermodynamic equilibrium (LTE) considerations early in the plasma decay. Focused laser radiation causes a reasonably high electron density, and increased particle-electron collision frequency, which facilitates LTE. One can estimate [21] the electron density, $\mathrm{N}_{\mathrm{e}}$, above which local equilibrium conditions prevail:

$$
\mathrm{N}_{\mathrm{e}} \gg 1.6 \times 10^{12} \sqrt{\mathrm{T}} \times(\Delta E)^{3} \mathrm{~cm}^{-3} \text {. }
$$

Here, $\mathrm{T}$ is the electron temperature and $\Delta \mathrm{E}$ is the transition energy in units of electron volts. For the Swan bands of $\mathrm{C}_{2}$ typically at $500 \mathrm{~nm}$, and with an electron temperature of $10000 \mathrm{~K}$, LTE is reached whenever $\mathrm{N}_{\mathrm{e}}$ is of greater magnitude than $10^{15} \mathrm{~cm}^{-3}$. This limit is easily surpassed for focused laser irradiation, as can also be seen from plasma diagnostic using atomic line profiles (see Figure 4).

In our analysis [16], the rotational line-strength factor, also called the Hönl-London factor (HLF), is one of the more important terms in the equations for diatomic line intensities. The relative intensities of diatomic spectral lines are primarily controlled by the state population density and the HLF. Computed diatomic spectra are of great

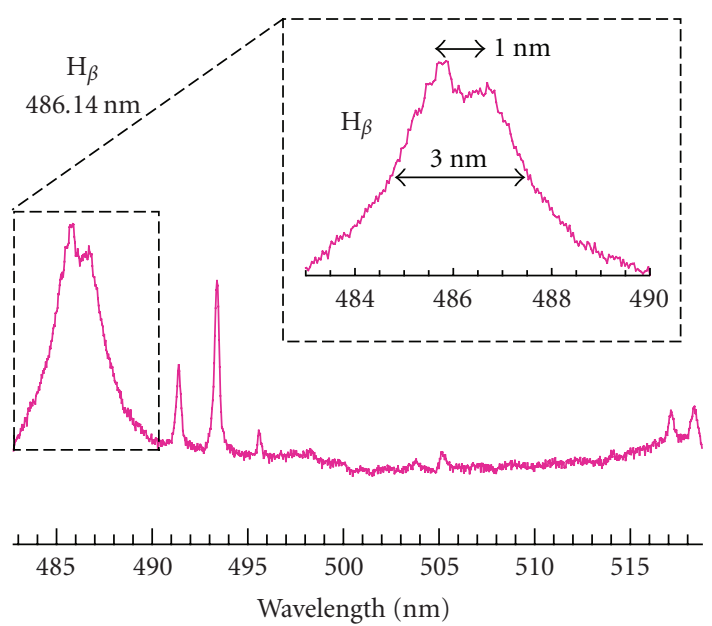

FIgURE 4: Recorded $\mathrm{H}_{\beta}$ emission in laboratory air. The insert shows $\mathrm{H}_{\beta}$ full-width-at-half-maximum of $3 \mathrm{~nm}$, and a peak separation of $1 \mathrm{~nm}$; consequently, the electron number density amounts to $\mathrm{N}_{\mathrm{e}} \cong$ $0.5 \times 10^{17} \mathrm{~cm}^{-3}$.

value because a comparison of a synthetic spectrum with a recorded spectrum allows one to compare experiment with theory. A comprehensive discussion on spectroscopy of carbon containing diatomic molecules addresses aspects of our analysis of measured diatomic molecular spectra [22].

Figure 4 shows the recorded spectrum of the H-beta line profile at a time delay of $10 \mu \mathrm{s}$, using a $10 \mu$ s gate. The source of hydrogen is water content in the flowing gas sample. The $\mathrm{H}_{\beta}$ Stark width and the separation of the $\mathrm{H}_{\beta}$ double peak structure is a measure for the free electron number density [23-26].

In our Nd:YAG laser experiments, repeated laser ablation of the stationary target reduced the plasma intensity and influenced appearance of kinetic curves for emission. Subsequent laser pulses usually harden the graphite surface, consequently, kinetic spectra were taken from a well-exposed target. Photographs of the plasma were captured using a standard Kodak digital camera. The photographs indicate that light emission occurred from three distinct sections: (i) from the plasma plume, (ii) from an illuminated laser beam, and (iii) from the ground glass vacuum joint of the LIBS cuvette. Spectra were recorded only from the laser plume area with the aid of a small fused silica focusing lens at the entry point of the fiber.

The kinetic spectral mode of the ICCD spectrograph indicated a strong time dependence of the carbon plasma emission. Figures 5(a)-5(e) show typical results of $\mathrm{C}_{3}$ broad $400 \mathrm{~nm}$ feature Swings bands and $\mathrm{C}_{2}$ Swan bands 450$575 \mathrm{~nm} \Delta v=+1,0,-1$ progression. These emission spectra were recorded following $355 \mathrm{~nm}$ Nd:YAG laser ablation of graphite in 70 Torr argon. A gate width of $\tau_{\text {gate }}=50$ ns was used at the indicated time delays of $250,370,490,610$, and 730 ns.

The decay of the $\Delta v=0$ Swan emission was further investigated versus time delay $\Delta \tau$. Figure 6 shows the $0-0$ band peaks/detector-counts above baseline, and it also shows 


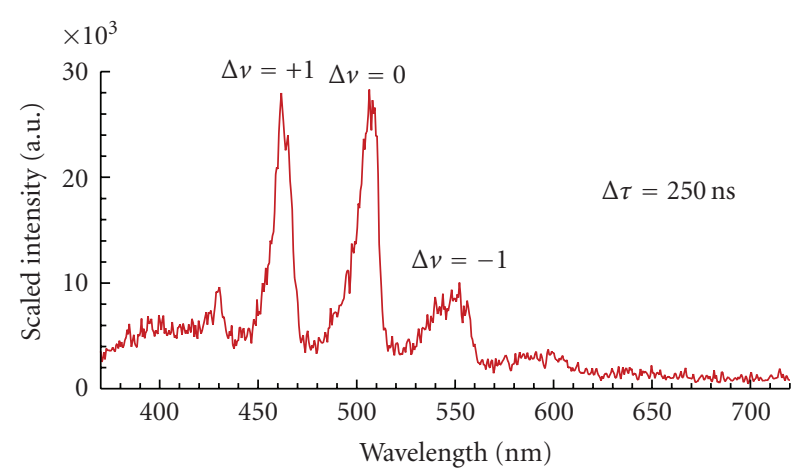

(a)

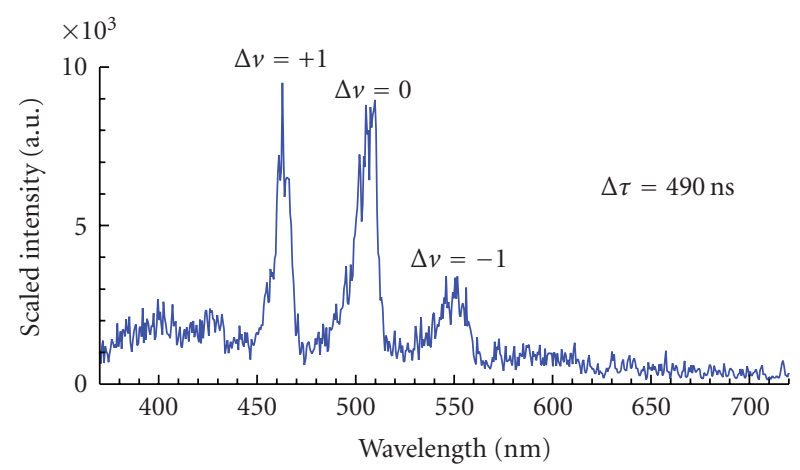

(c)

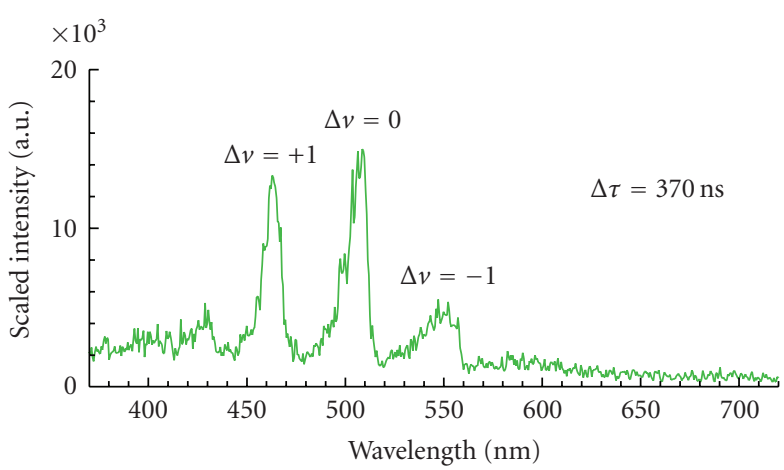

(b)

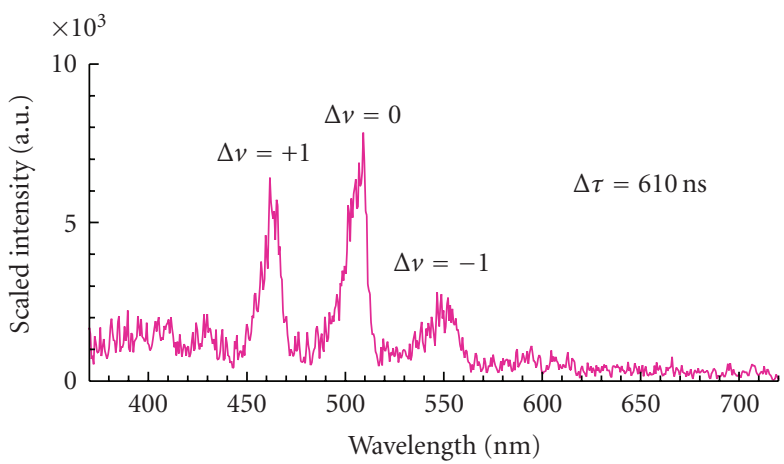

(d)

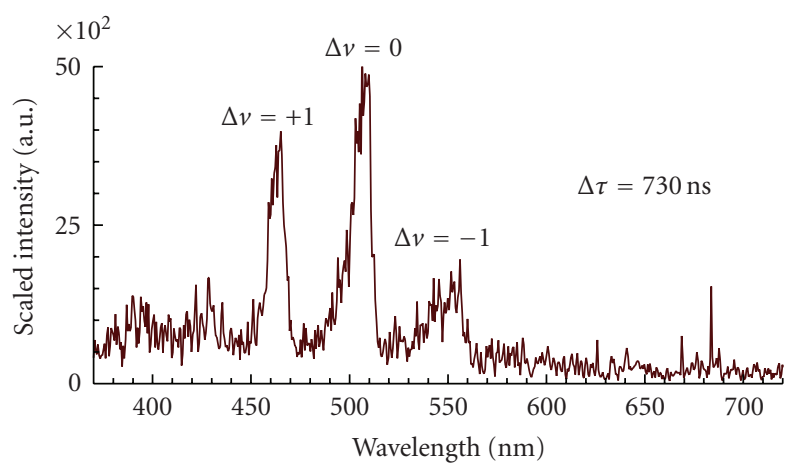

(e)

FIGURE 5: Emission spectra for (a) $\Delta \tau=250 \mathrm{~ns}$, (b) $\Delta \tau=370 \mathrm{~ns}$, (c) $\Delta \tau=490 \mathrm{~ns}$, (d) $\Delta \tau=610 \mathrm{ns,} \mathrm{(e)} \Delta \tau=730 \mathrm{~ns}$.

an exponential fit. The fitted decay time amounts to $132 \pm$ 3 ns.

Vibration-rotation temperatures for the Swan band lines for the $\mathrm{C}_{2}$ radical were inferred using an exact spectral simulation method $[19,20]$ that employs computed line strength values $[15,16]$. Figure 7 shows results for the temperature versus time delay from optical breakdown, and it also shows error bars. The vertical bars were estimated from fitting the $\Delta v=+1, \Delta v=0, \Delta v=-1$ progression. The horizontal bars indicate the intensifier gate width.

\section{Discussion of Experiments}

The spectra recorded in our $\mathrm{CO}_{2}$ laser experiments allow us to infer an electron number density of $0.6 \times 10^{17} \mathrm{~cm}^{-3}$ from the hydrogen-beta Stark-broadened profiles that were measured $10 \mu \mathrm{s}$ after plasma generation. Earlier in the plasma decay for time delays of a few microseconds, the $\mathrm{H}_{\beta}$ profiles indicate higher electron number density in excess of $5.0 \times 10^{17} \mathrm{~cm}^{-3}$. In comparison with nominal Nd:YAG laser-induced optical breakdown [24], we find that such freeelectron number densities occur at 10x shorter time delay when using nominal nanosecond Nd:YAG laser radiation for optical breakdown.

The spatial extent of the focal spot diameter for $10.6 \mu \mathrm{m}$ $\mathrm{CO}_{2}$ radiation is at least $10 \mathrm{x}$ larger than for $1.064 \mu \mathrm{m}$ Nd:YAG radiation, as can be computed from Gaussian beam propagation: $d_{0} \sim 2 f^{\#} \lambda$. The focal volume established with the $\mathrm{CO}_{2}$ laser will also be at least $1000 \mathrm{x}$ larger than the one established with the Nd:YAG laser, as can be expected from 


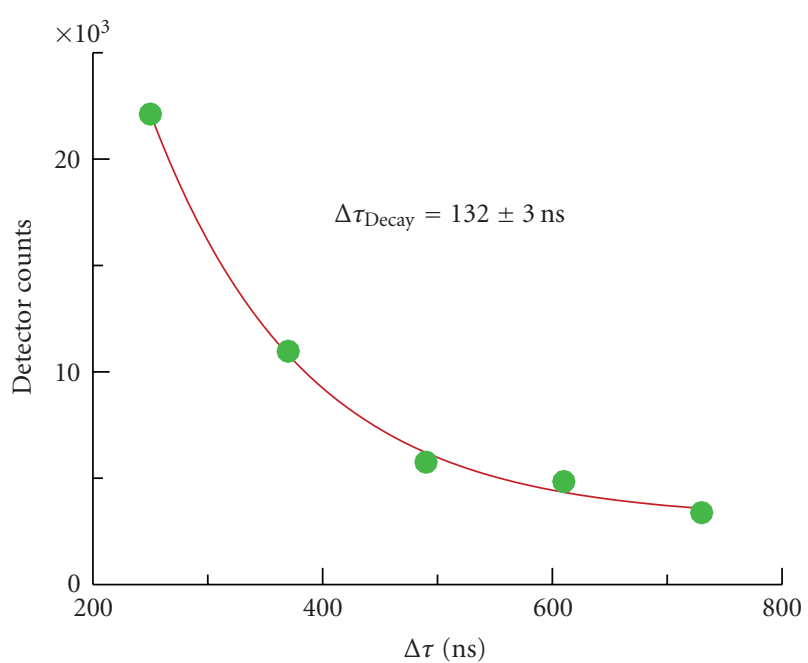

Figure 6: Measured and fitted detector counts for the $\Delta v=0$ Swan system of $\mathrm{C}_{2}$.

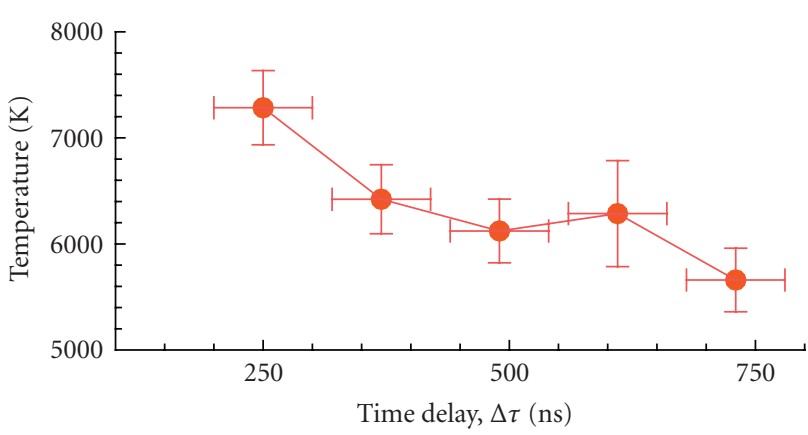

Figure 7: Inferred spectroscopic temperature versus time delay from optical breakdown.

the Gaussian beam result: $V_{\text {focus }} \sim 19.4\left(f^{\#}\right)^{4} \lambda^{3}$. Obviously, the actual focal spot diameter for $10.6 \mu \mathrm{m}$ radiation differs from Gaussian focusing due to typical spatial variations of the irradiance found for $\mathrm{CO}_{2}$ laser beams. For a $200 \mu \mathrm{m}$ focal radius the focal volume is estimated to be approximately $V_{\text {focus }} \sim 10^{-3} \mathrm{~cm}^{3}$. Also, for a focal radius of $\sim 100 \mu \mathrm{m}$ and $\sim 100$ ns pulses the peak irradiance amounts to $\sim 1 \mathrm{GW} / \mathrm{cm}^{2}$ for the $10.6 \mu \mathrm{m} \mathrm{CO}$ laser radiation. In comparison, a peak irradiance of typically $100-1000 \mathrm{GW} / \mathrm{cm}^{2}$ is achieved for optical breakdown in air with nominal nanosecond $1.064 \mu \mathrm{m}$ Nd:YAG laser radiation.

The recombination emission spectra from diatomic species, for example, $\mathrm{CN}$ or $\mathrm{C}_{2}$, clearly indicate temperatures in excess of 7000 Kelvin. Studies of the $\mathrm{CO}_{2}$ TEA laser-induced microplasmas show highly excited, hightemperature molecular transitions several tens of microseconds after plasma generation, mixed with signatures of Stark-broadened atomic lines. Our initial investigations reveal that the spectra recorded from the 10.6-micron laser-radiation-induced plasma show in principle similar plasma decay features as for the 1.064-micron Nd:YAG lasergenerated plasma. Noteworthy is the spatially larger $\mathrm{CO}_{2}$ laser generated plasma, with a homogenous appearance due to extended, approx $100 \mathrm{~ns}$ laser excitation/pumping. Spectroscopic fitting of superposed emission spectra will be of future interest, such as fitting of the $\mathrm{C}_{2}$ Deslandres D'Azambuja system near the 4-4 band of the CN $\Delta v=0$ sequence of the $\mathrm{CN} \mathrm{B}^{2} \Sigma^{+} \rightarrow \mathrm{X}^{2} \Sigma^{+}$Violet System.

We explored the possibility of exponentially fitting the time dependence recorded in our Nd:YAG laser experiment, see Figure 7. We found that the results are influenced by the ablation alterations of the graphite target. Moreover, graphite laser ablation can show double-peaked $\mathrm{C}_{2}$ emission [27], due to recombinational production of $\mathrm{C}_{2}$ molecules and due to dissociative laser-ablation of fragments that may be excited $\mathrm{C}_{2}$ molecules. The recombinational and dissociative mechanism is expected to favorably occur for higher and lower laser irradiance, respectively. The irradiance levels used in our time-resolved experiments appear to induce both processes. Revival of measured $\mathrm{C}_{2}$ emission signals seems to be indicated in Figure 5(d). This minute revival may lead to elevated temperature for that time delay as illustrated in Figure 7. Increased $\mathrm{C}_{2}$ emissions can also be caused by expansion dynamics in laser ablation [28]. It will be of interest in future work to address timedependent revival of $\mathrm{C}_{2}$ signals. However, the time decay fit illustrated in Figure 6 appears to contraindicate double peaking in temporal behavior. Moreover, double peaking may favorably occur only for longer time scale. It will also be of interest to investigate effects of the ablation modifications of the graphite target on the plasma emissions during our measurements.

The deposited ablation products on the walls of the quartz LIBS cell were further studied with visible absorption spectroscopy. For these measurements, we used the model Ocean Optics SP2000 miniature spectrometer. Separate deposits on small copper grids were studied employing transmission electron microscopy (TEM).

The absorption spectrum of the deposit is primarily due to amorphous carbon. The spectra exhibited no distinct features, only a gradual decrease of light absorption from the blue to the red regions. TEM pictures reinforced this conclusion as they show a uniform noncrystalline deposit devoid of special features.

The weakness of $\mathrm{C}_{3}$ emissions in our spectra is somewhat surprising as it has been known for a long time that the $\mathrm{C}_{3}$ radical is a dominant component of thermal equilibrium carbon vapors [29]. Some likely explanations for the weak emissions can be found by considering nonequilibrium conditions [30], electron collision cross-sections [31,32] and $\mathrm{C}_{3}$ cation formation [33] and slow intersystem crossing from triplet $C_{3}$ to singlet $C_{3}[34]$ in laser ablation plasma.

The time-resolved LIB spectra of laser-ablated graphite show a sharp temporal decay of the $\mathrm{C}_{2}$ Swan bands, as well as under some circumstances, the appearance of broad features near $400 \mathrm{~nm}$. The $400 \mathrm{~nm}$ feature in the laser-induced plasma spectra is likely due to occurrence of the Swings bands of the $\mathrm{C}_{3}$ radical. Theoretical calculations in recent literature suggest $[31,32]$ that the electron collision excitation crosssection of the $\mathrm{C}_{3}$ Swings band upper singlet state is smaller by a factor of about 35 than the excitation cross-section of the upper triplet state of the $\mathrm{C}_{2}$ Swan bands, therefore, the 
plasma conditions favor $C_{2}$ spontaneous emission over $C_{3}$ spontaneous emission.

In addition, regenerative sooting discharge studies [33] indicate that in electric discharges, similar in nature to laser-induced plasmas, the $\mathrm{C}_{3}$ cation $\left(\mathrm{C}_{3}{ }^{+}\right)$dominates, so it is likely that in our spectra the neutral $\mathrm{C}_{3}$ emission is weakened also by electron collision ionization of $\mathrm{C}_{3}$. The use of lower laser irradiance, by unfocusing the beam and by reducing the energy per pulse, results in diminished electron number density and causes at least a three-fold effect: firstly, local thermodynamic equilibrium (LTE) conditions are not achieved; secondly, electronic excitation of the $\mathrm{C}_{3}$ Swings bands is lessened; thirdly, and most importantly, $\mathrm{C}_{3}$ cation formation is lessened, thus it becomes more favorable to observe neutral $\mathrm{C}_{3}$ emission in our plasma. Another factor that may contribute to the weakness of $C_{3}$ Swings emission is that $\mathrm{C}_{3}$ arises in the plasma in triplet state and the conversion from this triplet to the upper state singlet state in Swings emission is a very slow, millisecond process [34].

\section{Conclusions}

Measurement and analysis of time-resolved emission spectra following laser-induced optical breakdown (LIOB) allows us to characterize microplasmas that contain carbon. Presence of hydrogen in the sample will result in Balmer series emissions, and particularly the $\mathrm{H}_{\beta}$ emission will be useful for determining plasma parameters. Detailed analysis of selected diatomic spectra, such as the Swan spectra, is accomplished by using line-strength files. Applications of our methods will be useful in the study of laser-induced breakdown phenomena, for example, laser-induced combustion and/or combustion augmentation, or laser-initiated nanoparticle generation.

\section{Acknowledgments}

This work is in part supported by UTSI's Center for Laser Applications and by the Hungarian Basic Research Foundation (OTKA), under contract no. T046271. The timeresolved spectroscopic equipment in the Research Institute for Chemistry of the Hungarian Academy of Sciences was supported by the European Infrastructure Project KMA-KPI GVOP-3.2.1.- 2004-04-0059/3.0.

\section{References}

[1] A. W. Miziolek, V. Palleschi, and I. Schechter, Eds., Laser Induced Breakdown Spectroscopy, Cambridge University Press, New York, NY, USA, 2006.

[2] D. E. Cremers and L. J. Radziemski, Handbook of Laser-Induced Breakdown Spectroscopy, John Wiley \& Sons, New York, NY, USA, 2006.

[3] J. Pender, B. Pearman, J. Scaffidi, S. R. Goode, and S. M. Angel, "Laser-induced breakdown spectroscopy using sequential laser pulses," in Laser Induced Breakdown Spectroscopy, A. W. Miziolek, V. Palleschi, and I. Schechter, Eds., chapter 15, Cambridge University Press, New York, NY, USA, 2006.
[4] D. K. Killinger, S. D. Allen, R. D. Waterbury, C. Stefano, and E. L. Dottery, "Enhancement of Nd: YAG LIBS emission of a remote target using a simultaneous $\mathrm{CO}_{2}$ laser pulse," Optics Express, vol. 15, no. 20, pp. 12905-12915, 2007.

[5] R. D. Waterbury, A. Pal, D. K. Killinger, J. Rose, E. L. Dottery, and G. Ontai, "Standoff LIBS measurements of energetic materials using a 266nm excitation laser," in Chemical, Biological, Radiological, Nuclear, and Explosives Sensing IX (CBRNE '08), vol. 6954 of Proceedings of SPIE, The Optical Society of America, Orlando, Fla, USA, March 2008, CD-ROM, paper LThC4.

[6] M. Weidman, S. Palanco, and M. Richardson, "Thermodynamic properties of a $\mathrm{Nd}$ : YAG- $\mathrm{CO}_{2}$ double pulse laserinduced plasma and its applications under stand-off conditions," in Proceedings of the Applications to Chemical, Security and Environmental Analysis (LACSEA '08), The Optical Society of America, St. Petersburg, Fla, USA, March 2008, CD-ROM, paper LThC5.

[7] C. López-Moreno, S. Palanco, J. J. Laserna, et al., "Test of a stand-off laser-induced breakdown spectroscopy sensor for the detection of explosive residues on solid surfaces," Journal of Analytical Atomic Spectrometry, vol. 21, no. 1, pp. 55-60, 2006.

[8] A. W. Miziolek, F. C. DeLucia, C. A. Munson, and J. L. Gottfried, "Recent progress in LIBS-based technologies for security applications," in Proceedings of the Applications to Chemical, Security and Environmental Analysis (LACSEA '08), The Optical Society of America, St. Petersburg, Fla, USA, March 2008, CD-ROM, paper LThC1.

[9] M. Z. Martin, M.-D. Cheng, and R. C. Martin, "Aerosol measurement by laser-induced plasma technique: a review," Aerosol Science and Technology, vol. 31, no. 6, pp. 409-421, 1999.

[10] P. I. Singh, "Experiments on Aerosol Induced Breakdown by Pulsed Lasers," in Proceedings of the 17th AIAA Aerospace Sciences Meeting, New Orleans, La, USA, January 1979, AIAA paper 1979-0249.

[11] C. G. Parigger, "Laser-induced breakdown in gases: experiments and simulation," in Laser Induced Breakdown Spectroscopy, A. W. Miziolek, V. Palleschi, and I. Schechter, Eds., chapter 4, Cambridge University Press, New York, NY, USA, 2006.

[12] C. G. Parigger, J. O. Hornkohl, A. M. Keszler, and L. Nemes, "Measurement and analysis of atomic and diatomic carbon spectra from laser ablation of graphite," Applied Optics, vol. 42, no. 30, pp. 6192-6198, 2003.

[13] L. Nemes, A. M. Keszler, J. O. Hornkohl, and C. G. Parigger, "Laser-induced carbon plasma emission spectroscopic measurements on solid targets and in gas-phase optical breakdown," Applied Optics, vol. 44, no. 18, pp. 3661-3667, 2005.

[14] J. O. Hornkohl, C. Parigger, and J. W. L. Lewis, "Temperature measurements from CN spectra in a laser-induced plasma," Journal of Quantitative Spectroscopy and Radiative Transfer, vol. 46, no. 5, pp. 405-411, 1991.

[15] J. O. Hornkohl and C. G. Parigger, Boltzmann Equilibrium Spectrum Program(BESP), The University of Tennessee Space Institute, Tullahoma, Tenn, USA, 2002, http://view.utsi.edu/besp/.

[16] J. O. Hornkohl, C. G. Parigger, and L. Nemes, "Diatomic HönlLondon factor computer program," Applied Optics, vol. 44, no. 18, pp. 3686-3695, 2005.

[17] H. S. Park, S. H. Nam, and S. M. Park, "Time-resolved optical emission studies on the laser ablation of a graphite target: The 
effects of ambient gases," Journal of Applied Physics, Article ID 113103, 2005.

[18] "Atomic emission line data are obtained using the NIST Atomic Spectra Database Lines Form," http://physics.nist .gov/PhysRefData/ASD/.

[19] C. Parigger, D. H. Plemmons, J. O. Hornkohl, and J. W. L. Lewis, "Spectroscopic temperature measurements in a decaying laser-induced plasma using the $\mathrm{C}_{2}$ Swan system," Journal of Quantitative Spectroscopy and Radiative Transfer, vol. 52, no. 6, pp. 707-711, 1994.

[20] L. Nemes, A. M. Keszler, J. O. Hornkohl, and C. G. Parigger, "Laser-induced carbon plasma emission spectroscopic measurements on solid targets and in gas-phase optical breakdown," Applied Optics, vol. 44, no. 18, pp. 3661-3667, 2005.

[21] A. Thorne, U. Litzén, and S. Johansson, Spectrophysics, Principles and Applications, Springer, Berlin, Germany, 1999.

[22] J. O. Hornkohl, L. Nemes, and C. G. Parigger, "Spectroscopy, dynamics and molecular theory of carbon plasmas and vapors," in Advances in the Understanding of the Most Complex High-Temperature Elemental System, L. Nemes and S. Irle, Eds., World Scientific, 2009.

[23] R. Zukić, M. A. Gigosos, M. Ivković, M. Á. González, and N. Konjević, "A program for the evaluation of electron number density from experimental hydrogen balmer beta line profiles," Spectrochimica Acta Part B, vol. 57, no. 5, pp. 987-998, 2002.

[24] C. G. Parigger, D. H. Plemmons, and E. Oks, "Balmer series $\mathrm{H}_{\beta}$ measurements in a laser-induced hydrogen plasma," Applied Optics, vol. 42, no. 30, pp. 5992-6000, 2003.

[25] C. G. Parigger, M. Dackman, and J. O. Hornkohl, “Timeresolved spectroscopy measurements of hydrogen-alpha, beta, and -gamma emissions," Applied Optics, vol. 47, no. 31, pp. G1-G6, 2008.

[26] S. Djurović, M. Ćirišan, A. V. Demura, et al., "Measurements of $\mathrm{H}_{\beta}$ Stark central asymmetry and its analysis through standard theory and computer simulations," Physical Review E, vol. 79, no. 4, Article ID 046402, 14 pages, 2009.

[27] S. S. Harilal, "Expansion dynamics of laser ablated carbon plasma plume in helium ambient," Applied Surface Science, vol. 172, no. 1-2, pp. 103-109, 2001.

[28] S. S. Harilal, C. V. Bindhu, M. S. Tillack, F. Najmabadi, and A. C. Gaeris, "Internal structure and expansion dynamics of laser ablation plumes into ambient gases," Journal of Applied Physics, vol. 93, no. 5, pp. 2380-2388, 2003.

[29] A. V. Orden and R. J. Saykally, "Small Carbon Clusters: Spectroscopy, Structure and Energetics," Chemical Reviews, vol. 98, p. 2313, 1998.

[30] L. Nemes, A. M. Keszler, C. G. Parigger, J. O. Hornkohl, H. A. Michelsen, and V. Stakhursky, "Spontaneous emission from the $\mathrm{C}_{3}$ radical in carbon plasma," Applied Optics, vol. 46, no. 19, pp. 4032-4040, 2007.

[31] G. Halmová, J. D. Gorfinkiel, and J. Tennyson, "Low-energy electron collisions with $\mathrm{C}_{2}$ using the R-matrix method," Journal of Physics B, vol. 39, no. 12, pp. 2849-2860, 2006.

[32] H. Munjal and K. L. Baluja, "Elastic and excitation processes of electron impact on $\mathrm{C}_{3}$ using the R-matrix method," Journal of Physics B, vol. 39, no. 16, pp. 3185-3198, 2006.

[33] S. A. Janjua, M. Ahmad, S. Khan, R. Khalid, and S. Ahmad, " $\mathrm{C}_{3}$ as the dominant carbon cluster in high pressure discharges in graphite hollow cathodes," Journal of Physics D, vol. 40, pp. 1416-1421, 2007.
[34] G. Larsson, The $C_{3}$ molecule: A Literature Study and Spectroscopic Investigations in Flames and on Graphite, Lund Reports on Combustion Physics, LRCP-82, Lund Institute of Technology, Lund, Sweden, 2002. 


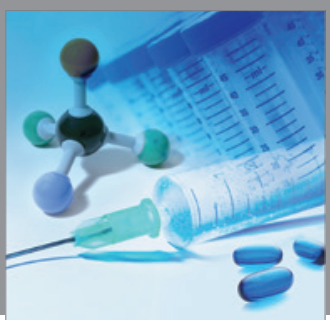

International Journal of

Medicinal Chemistry

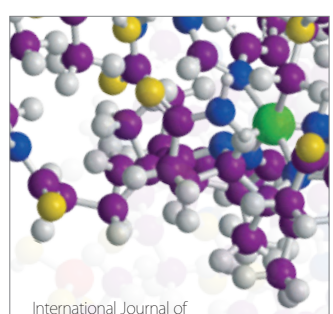

Carbohydrate Chemistry

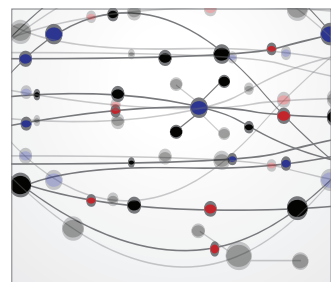

The Scientific World Journal
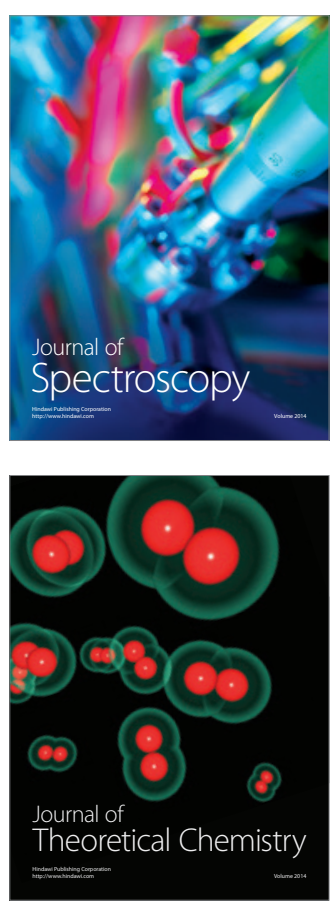
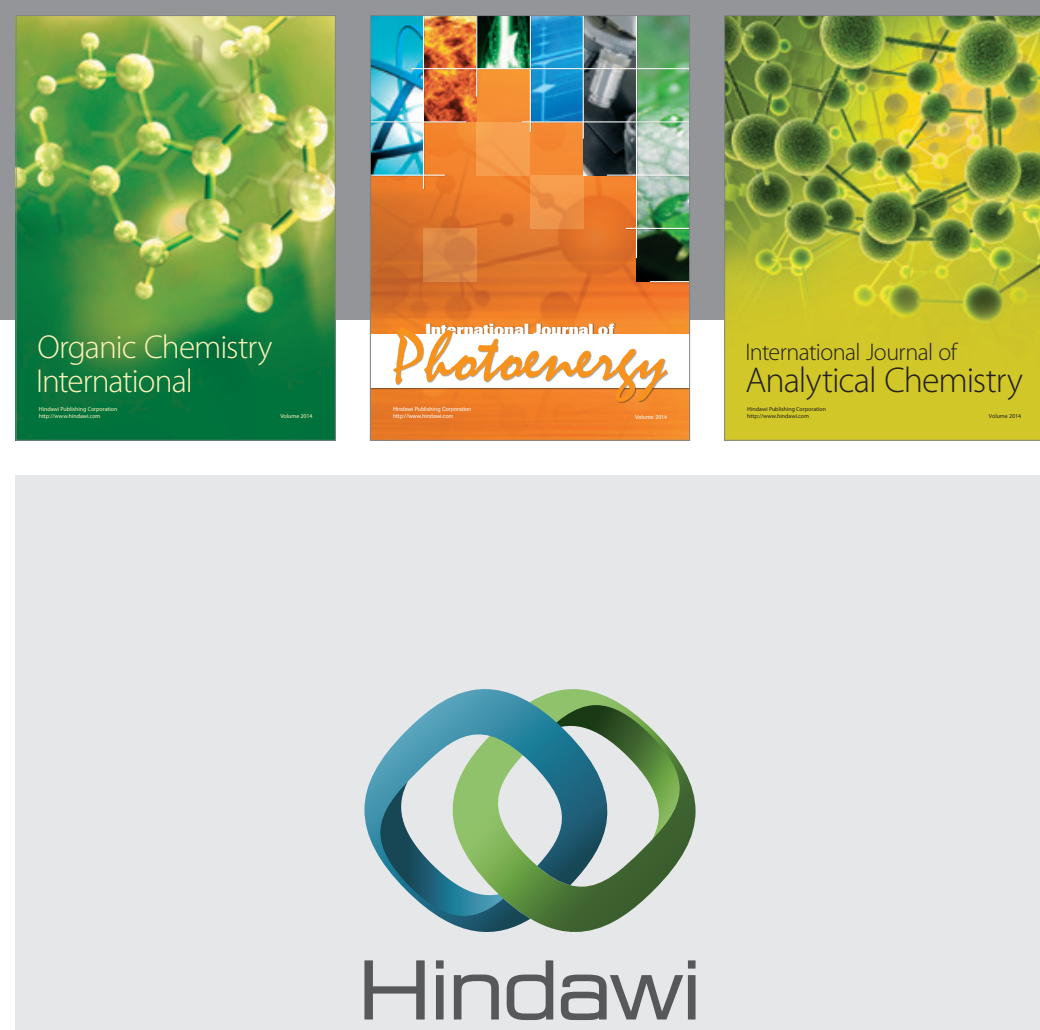

Submit your manuscripts at

http://www.hindawi.com
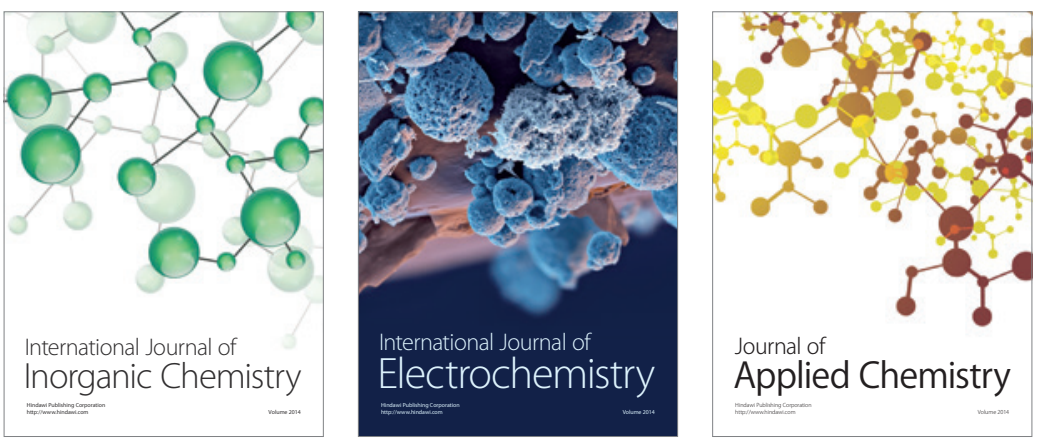

Journal of

Applied Chemistry
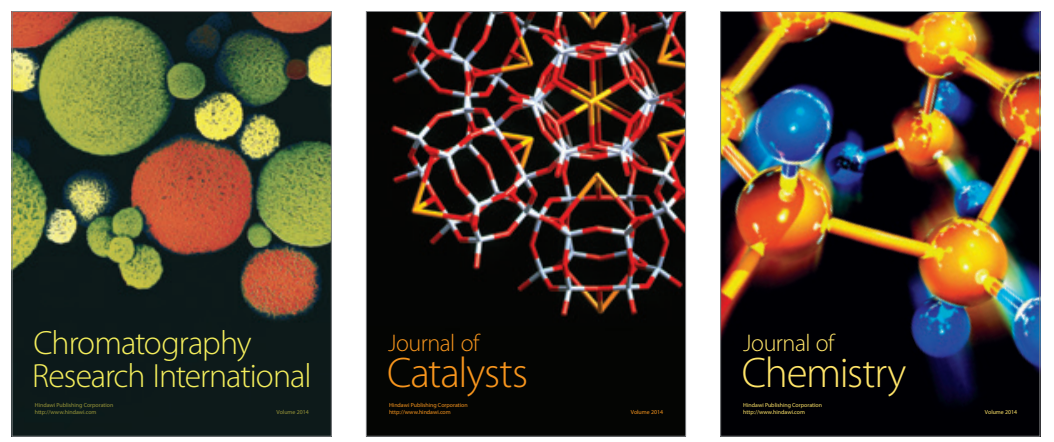
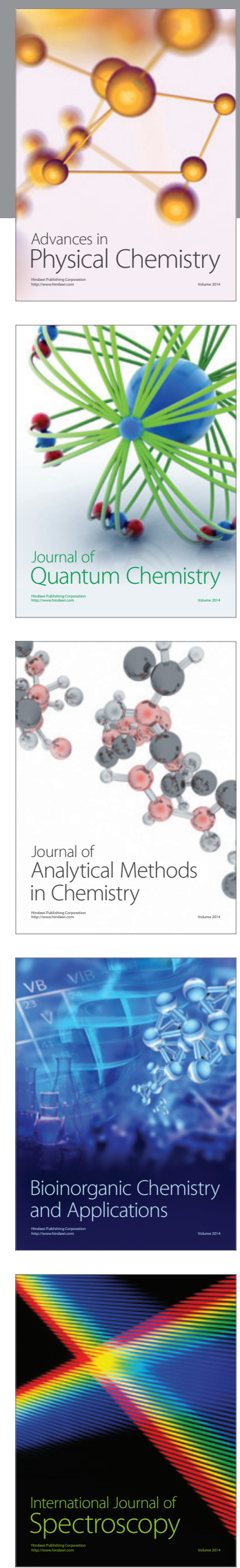